\title{
Equilibrium Point for a Stakeholder Management Strategy in Crisis Episodes: the Case of a Crisis
}

\author{
in a Food Processing Plant
}

\author{
Sylvain Charlebois \\ Lisa Watson \\ Faculty of Business Administration, University of Regina \\ Education Building, room ED508.1, 3737 Wascana Parkway \\ Regina, Saskatchewan S4S 0X2, Canada \\ Tel: (306) 337-2695Ｅ-mail: sylvain.charlebois@uregina.ca
}

\begin{abstract}
The aim of this paper is to shed light on the way organizations that collaborate in multi-stakeholder networks organize their crisis management readiness. It argues that crisis management practices differ significantly based on whether or not organizations are supply or demand over-dependent. In equilibrium between demand and supply, an organization is able to rely on non-linear connectedness and interdependence to foster relationships in the supply chain during a crisis. In this paper, we analyze the case of a food safety crisis that occurred in 2008 at a Canadian-based processing plant and challenge the current conventions. Finally, conclusions concerning the implementation of the framework together with limitations and future research directions are presented.
\end{abstract}

Keywords: Food safety, food recall, risk management, crisis management, food distribution 


\section{Introduction}

In August 2008, Canada experienced one of the worst epidemics of listeriosis in history. The epidemic resulted in a massive nationwide recall of over 230 food products, but the recall could not prevent the death of 20 people. In recent years, the increased frequency of food recalls and comparable incidents has exposed the real potential for food supply chain contamination and disruptions (Shang and Hooker, 2005).

This paper asserts the importance of an integrated strategy for dealing with a crisis. It also recognizes that in order to develop an effective crisis management plan, the process must be multi-faceted. Many large and well-known companies have embraced this idea and refer to their stakeholders as partners or collaborators. Globalization has made all organizations more interconnected. Any breakdown in a globalized system creates turbulence that will reverberate throughout most of its components.

The aim of this paper is to shed light on the way organizations that collaborate in multi-stakeholder networks organize their crisis management readiness. It argues that crisis management practices differ significantly based on whether or not organizations are supply or demand over-dependent. The paper starts by presenting some principles of stakeholder and crisis management theory, and highlighting their dominant inclination toward providing static taxonomic food distribution descriptions. Secondly, the paper presents a framework that provides a network perspective to crisis management. Next, we analyze the case of a food safety crisis that occurred in 2008 at a Canadian-based processing plant and challenge the current conventions. Finally, conclusions concerning the implementation of the framework together with limitations and future research directions are presented.

\section{Stakeholder Theory}

\subsection{Consumer Confidence}

A public health crisis can affect many industries (Johnson and al., 2008). In particular, the food industry and the agricultural sector have seen its share of crises (Creedle, 2007; Surak, 2007; Hirschauer and Zwoll, 2008). Magnitude of food recalls (i.e. severity of outcomes) coupled with media coverage affects consumer risk perceptions (Shumaker and al., 2003; Potts and Nelson, 2008). Planning for crises is essential for any stakeholder and is also a significant concern when considering public health risks. Because of unpredictability and market turbulence in global environments, traditional planning method for crises that assume linear intensification are being replaced by more scenario-based and systemic planning (Tan and Enderwick, 2006).

Consumers are increasingly more concerned about food safety and food-borne illnesses (Kornelis and al., 2007). More than ever, consumers exhibit multiple information-acquisition patterns which most certainly influence crisis management strategies. Nonetheless, most foodborne diseases are the result of improper domestic food handling (Fisher, Frewer and Nauta, 2006). These incidences can influence consumers' risk perception, which in turn can compromise consumer trust levels. Consumer trust should not be conceptualized as associated simply with consumer behavior, but as the more extrinsic quality of 
trustworthiness. Food systems are shifting from being trust dependant to trustworthy-focused. Transparency and traceability are common qualities that promote trustworthiness in food and agriculture.

Additional issues in food distribution have become sources of concern for consumers. Biotechnologies, growing distances between production, consumption spurred by globalization and an increase in the number of food recalls have contributed to significant changes within supply chains (Nabe, 2003; Aldoory and Van Dyke, 2006: Meijboom, Visak and Brom, 2006; Potts and Nelson, 2008).

\subsection{Systemic Approach}

Over time, many organizations have failed to foresee potential threats to the viability of their operations (Levick and Pudles, 2007). Since the food chain from producer to the end-consumer is recognized to be highly interconnected and dynamic, threats can appear suddenly (Desmarchelier and Szabo, 2008).

As result, stakeholder management has been gaining in popularity (Roloff, 2008). Stakeholder theory addresses morals and values when managing an organization (Reynolds, Schultz and Hekman, 2006; Roloff, 2008). Stakeholder theory is often applied to a corporate responsibility context (Cheah, Chan and Chieng, 2007; Jamali, 2008). Public officials involve stakeholders because greater stakeholder involvement seems to achieve higher acceptance of outcomes (Bayley and French, 2008).

Some argue that stakeholder networks are critical in uncertain times. Roloff (2008) suggests that organization-focused stakeholder management is mainly focused on relationship management and that its strategic actions comply with organizational interests. Issue-focused stakeholder management can promote more sustainable solutions by providing social capital such as trust and knowledge about the issue.

In the food industry, organizations tend to be product-centric, with narrowly defined product goals during crises (Pang, Cropp and Cameron, 2006). Organizations are tempted to play a dominant advocate role rather than an accommodating role within its environment (Pang, Cropp and Cameron, 2006).

The multi-stakeholder network approach reflects a new trend that unites business and society (Roloff, 2008). Multinationals are increasingly compelled to resolve social and economical unbalances created by international business activities (Charlebois, 2008). Palazzo and Scherer (2006) suggest that moral legitimacy has become the principal means for social acceptance and that companies have to engage in public communication.

A sound stakeholder management strategy in crisis episodes requires the ability to recognize and comprehensibly manage emerging and heterogonous issues involving stakeholders (Acquier, Gand and Szpirglas, 2008). Anchorage points should be identified quickly in a crisis management strategy involving many stakeholders. Primary motives for organization to enhance risk management capabilities are global competition, technological change and need for competitive advantage (Ritchie and Brindley, 2007). Paraskevas (2006) suggests that 
planning for a crisis is the art of eliminating much of the risk and uncertainty to attain more control over the destiny of the operation. Crises become increasingly complex in time as they transbound and interconnect many elements at once (Paraskevas, 2006).

\subsection{Communication and Technology}

In crisis management, non-linear dynamics should be used when determining how interest groups or other uncontrollable variables evolved over time (Murphy, 1996). Organizations, particularly those in the food industry, need to switch from a mechanical or architectural approach in crisis management to a more organic approach that will rapidly identify emerging threats (Paraskevas, 2006). Communication, or risk communication, is also key in times of crisis. Risk communication is fundamental when dealing with a crisis and creates opportunities for renewal (Ulmer, 2007). Some have questioned the traditional one-way corporate method of communicating in a crisis situation. A more participative, interactive approach may be more suitable (Gonzàlez-Herrero and Smith, 2008). If no interconnectedness exists between stakeholders in a network, breakdowns in communication will likely occur.

Crises are inevitable. Proper crisis management is not only reactive, and targeted toward crash management, but also proactive and interactive, stressing the necessity of continuous learning (Pauchant and Mitroff, 1992).

Learning is facilitated by technology. The use of technology in crisis management is critical. Technology allows organizations to prevent crises. However, extreme preparation for crises may lead to systems that are traditionalist, as crisis management acts as a brake on progress (Pauchant and Mitroff, 1992). Technology can prepare organizations to better deal with crises and share accountability.

In regards to elements such as communication and technology, Lindgreen (2003) suggests that trust derives from relationships in which partners have common core values. As long as trust exists between organizations, lack of control is often not experienced, or at least is not considered as an unpleasant vulnerability or dependency.

\subsection{Trustworthiness}

Enhancing trustworthiness requires an appropriate distribution of responsibility (Meijboom, Visak and Brom, 2006). Trustworthiness implies more than just transparency and providing information to consumers (Hudson and Hudson, 2008). Both are important but not nearly sufficient. Consumers want to know not only what the food industry is doing, but are compelled to know the purpose behind every such action. As a result, the values and ideals of every organization are important to the sharing cycle in which stakeholders are engaged. This sharing architecture that allows information and knowledge to flow will be heavily influenced by values embedded in organizational cultures.

Traceability and transparency in food supply chains are most affected by three forces: globalization, consolidation and commoditization (Roth and al., 2008). Pressures for cost reduction throughout the food supply chain driven by enhanced competition have contributed 
to the growth of food trades between nations. Consolidation has been a main driver within the food industry and resulted in economies of scale. Most consumers in developed countries can afford to eat more or less food products (Creedle, 2007). Finally, since consumers want to know the origin of food products, many large organizations are required to commoditize products when attaining new markets.

\section{Equilibrium Point}

The following visual representation of the equilibrium state of crisis management readiness was inspired by watching young children play with wooden blocks. The children were trying to balance blocks with the goal of building a chain and connecting elements together. Each middle block had to be positioned solidly between the two blocks above and below it in order to make everything hold together. The children were neglecting this principle and thus the wobbly product would not stand.

In times of crisis, organizations need to achieve a similar balance inside the supply chain. As shown in Figure 1, although an organization can never attain the equilibrium point, this ideal should always be its objective. In equilibrium, an organization is able to rely on non-linear connectedness and interdependence to foster relationships in the supply chain. It is recognized that demand and supply connectedness are equally important (Autry and Griffis, 2008). Trust and value sharing is achievable. The flow of information and knowledge leverages traceability and transparency. To accomplish this, technology is indispensable. Robert and Lajtha (2002) contend that the key to a valuable crisis management lies in structured and continuous learning processes for organizations. Strategic outputs are thrown back into the loop as a strategic input for the supply chain. Continuous learning for the entire supply chain therefore becomes likely. Preparations for sudden and the unexpected scenarios are preferred over detailed crisis management plans. Lagadec (2004) argues that we should switch from a mechanical or an architectural form of crisis management to a more organic approach to grasp and manage emerging crises.

An organization's position will shift continuously and may lean too much towards supply or demand. As such, when the state of disequilibrium occurs, demand or supply may influence an organization's ability to communicate with its environment. A shift may be triggered by demand or supply overdependence. These situations may vary across the supply chain. Stakeholders may vertically integrate due to environmental uncertainty, which may alter the amount of power an organization has within the supply chain (Charlebois and Camp, 2007). The precise supply chain path for a particular food product depends on product characteristics (Roth and al., 2008). 
Figure 1

Equilibrium Point for Stakeholder Management

Strategy in Crisis Episodes

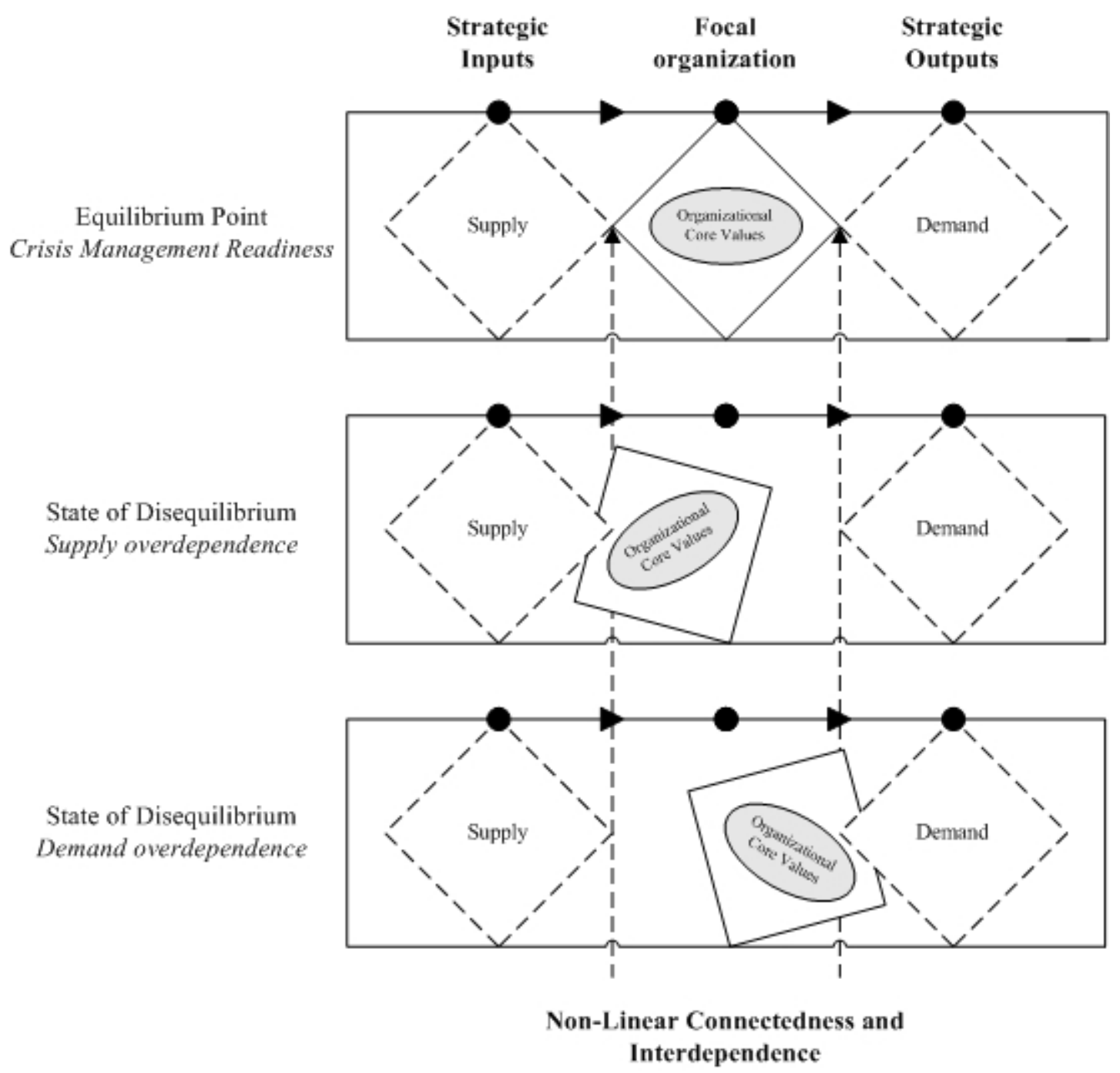

Power, dependence and influence strategies have proven to be useful theoretical perspectives when understanding supply chain behaviors (Emerson, 1962). The retailer may depend on the manufacturer for products and a reliable stream of purchasers for those products. On the other hand, the manufacturer depends on the retailer to provide a critical part of the marketing and selling functions of the brand (Blattberg and Neslin 1990, Kotler 1994). Attention to food safety shifts the power balance throughout the supply chain and makes stakeholders demand more control. Supply chains also have dominant organizations in a vertical marketing system that controls the Channel of Distribution. Thus, the more an organization is vertically integrated, the more its power will consequently trigger dependence disequilibrium (Charlebois and Camp, 2007). This company has a major influence on what products or services are developed and distributed throughout the chain. It is also important to note that organizations which participate in little or no collaboration with other stakeholders are likely to be unaware of any disequilibrium. 


\section{Research Design}

As stated earlier, this paper proposes a stakeholder-oriented framework for effective crisis response. To achieve its objective, the case study approach was utilized to offer a holistic and comprehensive understanding of organizational and systemic crisis contexts and the crisis response processes followed before and during the crisis. Yin (1993) argues that the case study approach is ideal in these matters.

The case study is a rewarding approach because it has considerable ability to provide answers in the explanation-building process (Robson, 1993). This paper attempts to build a theory from the literature while collecting and analyzing data. As such, this paper attempts to identify a set of explanations and causal links to explain phenomena (Yin, 1994). Case studies in crisis management have been recognized as self-serving, but may also provide useful evaluation and benchmarking for any organization (Jacques, 2008).

The case of a food processing plant faced with a major crisis during the summer of 2008 was chosen for the investigation. The data were collected through a formal set of interviews with managers of several organizations involved in the response of the crisis. In addition to the multinational company that owns the plant, organizations included in the study were input suppliers, customers (food distributors and retailers), and public health agencies (federal and provincial). Key informants representing these organizations were general managers, directors and, in some cases, owners. Most were involved with marketing, public relations and operations.

This case garnered international attention and many may be familiar with it. However, due to the sensitivity of the case all information was kept confidential, anonymity has been maintained and every reasonable effort was made to adequately conceal the organizations involved.

A total of 5 interviews were conducted, of which 3 were with members of the organization stricken by the crisis. All interviews were conducted by phone. No customers of the organization were interviewed. The interviews involved in-depth one-to-one discussion with the respondent and lasted 60 to 100 minutes on average. Respondents were asked to recall the events from their own perspective. These perspectives provided a holistic and multifaceted view to the issue. All interviews were digitally-taped and transcribed. The analysis of each testimony enabled the study to derive perceptions on experience and understand relationships between events and actions taken during the crisis. Being detached from the experience itself, the principal investigator was able to connect variables to relate all parts of a whole, in so far as it is possible, and make connections with theory. Secondary data collected from newspaper and magazine reports were also considered in the analysis.

\section{Anatomy of a Crisis}

The organization has incorporated the Hazard Analysis and Critical Points (HACCP) principles in every phase of food production and has an ISO9002 and HACCP certification by a major European testing and certification agency. These, combined with an excellent 
public relations plan which has been developed over several years, gave the organization confidence that could deal with several crisis scenarios.

The organization is a well-known multinational with well over 100 years of existence. Its best-known brands are sold across Canada. Sales for 2007 were 5.21 billion \$CAN, of which $71.6 \%$ came from the Canadian market, $52 \%$ from meat products and $27.5 \%$ from bakery products. Profits in 2007 were at 207 million \$CAN. The organization employs a total number of about 23,500 employees.

The first symptoms emerged in June 2008 when public health units in Ontario noted an increase in listeriosis cases. While four or five cases are normally reported, the number climbed to seven or eight, but that deviation was not yet significant. In mid-July, Toronto Public Health ramped up its investigation after a case of listeriosis was discovered at a nursing home. Investigators took food samples from the home and sent them to a Health Canada laboratory. By late July, Ontario's Health Ministry asked local health units for more details to judge whether the increase in listeriosis cases was significant. Before declaring an outbreak, provincial officials looked for clusters of cases of the same listeria organism, based on genetic tests (Attaran and al., 2008).

On August 5 2008, Health Canada tests showed a sandwich from a nursing home in Toronto was contaminated with listeria. The following day, Toronto Public Health notified the Canadian Food Inspection Agency (CFIA) of the positive food samples. On August 13, the organization sent a letter to distributors to inform them that the company is being investigated by the CFIA. The organization collected Sure Slice roast beef, corned beef and black forest ham products for testing and eventual disposal. On August 16, the organization acknowledged that its Sure Slice roast beef tested positive for listeria.

On August 17, the organization voluntarily recalled Sure Slice roast beef and corned beef, amounting to 23 products from its Toronto-based plant. At the same time, the organization prepared to recall more products after later tests confirmed listeria in its Sure Slice roast beef and corned beef. On August 20, Federal officials reported one death and 16 other cases have been linked to the listeriosis outbreak. The organization announced on the same day that it was expanding its recall of packaged meats, including a variety of turkey, smoked meat and roast beef products prepared at its Toronto plant since June 2. The company closed the entire factory to re-evaluate its food safety procedures.

On August 23, tests firmly established a link between the deadly nationwide outbreak of listeriosis and meat products from the organization which prompts it to expand its recall to include all 220 items produced at its Toronto plant as a precaution. On August 25, Lucerne Meats announced the recall of some Mac's and Safeway sandwiches in Western Canada because some of the food contained meat from the organization's August 24 recall.

At this point, the recall's scope was broadening nationally. In Atlantic Canada, on August 26, Atlantic Prepared Foods Ltd. recalled its Irving, Sub Delicious and Needs brand sandwiches sold in the Maritimes because the ready-made sandwiches may contain some of the meat products recalled by the organization. Metro Ontario Inc. pulled some of its Fresh 2 Go 
sandwiches from A\&P and Dominion stores for the same reason. By that time, Public Health Authority of Canada officials stated there were 15 deaths, mostly in the province of Ontario, but also one each in the province of British Columbia., Saskatchewan and Quebec.

On August 27, the organization decided it would bear full responsibility for the distribution of meat that led to the deadly national outbreak. The same day, law firms in Ontario and Alberta started legal action against the organization. Meanwhile, Federal inspectors were accused of spending insufficient time on the factory floor and relying more on food producers to monitor themselves via third parties.

On September 3, Prime Minister Stephen Harper pledged an independent investigation into the outbreak, days before a Federal election was called. On September 5, the organization reported that two slicing machines at the company's Toronto plant were believed to be the most likely source of listeriosis that led to the deadly outbreak.

\section{Data Collection}

Prior to the crisis, the organization had significantly invested in the development of food safety systems and crisis management plans using consulting firms. The organization's reputation in food safety was considered to be excellent (Bonnell, 2008). Even so, demand connectedness extended the recall to an exceptional level (Autry and Griffis, 2008). The recall included private labels, major restaurant chains and points of purchase at retail. One internal employee was confident that the organization was able to cope with the situation but was surprised by the enormity of the situation:

We had conducted many surveys and exercises with partners and within the company. Scenarios were similar but not in such a scale. The recall was massive and beyond our beliefs. It was highly unexpected. We did not expect to see such an enormous outbreak (Executive committee member).

In an evaluation meeting during the aftermath of the crisis, another member of the executive team commented:

The results were disappointing. It was entirely our fault and we failed to protect the chain. We were right to accept all the blame unequivocally. Even though we have strict procedures, for some reason, we missed that machine. What looks good on paper does not really work in practice.

Although the organization embraced crisis management and rigorous food safety systems for years, no collective training was offered or conducted with suppliers or clients (Wang, 2008). No systemic or transversal culture was created (Hirschauer and Zwoll, 2008). In the aftermath of the crisis, one member of the executive committee commented on this issue:

As an organization, we had the foresight to invest on food traceability planning and training. We were very myopic in terms of deployment as we assumed our customers would follow suit and be as informed as were on the situation. 


\section{Al Macrothink}

Research in Applied Economics

ISSN 1948-5433

2009, Vol. 1, No. 1: E4

The organization's approach to the crisis seemed to have been anything but systemic (Lagadec, 2004). Some managers did not know what to do. They were given detailed sequence of tasks aiming at effective crisis response but were unsure about the overarching strategy:

All actions were mechanical and we did not know why we did what we did. We were not sure what do to with recalled products. The policy was not clear, still isn't to this day. We were asking consumers to throw products out but some were asking for reimbursements. Our own clients, distributors, restaurants chains were asking us questions we couldn't answer. We all understood that we had to deal with public relation issues and try to minimize the negative image that this crisis could cause but we could only guess that each specific action we were taking would contribute to an entire design.

The crisis response system was well-designed in terms of providing information to customers and the market (Gonzalès and Smith, 2008). A website was set up and dedicated to the crisis. The reporting system worked well. But it was reported that the website and public relations strategy failed to establish a relationship that allowed for sharing of information within the supply chain (McCargar and al., 2003). One executive committee member stated the following:

The flow of information was sufficient coming to our plant. Everyone did an excellent job. Information collection was functional but it was challenging though to communicate properly with our clients during the crisis and share information in real-time. In retrospect our crisis website could be used more effectively. The website was designed for us, not for our partners.

This point about the crisis website was affirmed by all of the respondents in the unit. The flow of information was abundant but was basically unidirectional (Gonzalès and Smith, 2008). The organization was issuing directives for executives without any further information about the situation across the supply chain.

I knew what was happening in different stores and clients because I or my colleagues took the initiative to communicate with each other. The intranet limited information to our partners. Most of the critical information that our partners or even the general public wanted to know was provided by the CFIA. We needed that information from the market.

Supply connectedness was questioned by some respondents (Franck and al. 2006). The relationship with suppliers was anything but evident. Respondents stated that suppliers were informed of the situation but were not considered as crucial in the overall scheme.

Our suppliers were regularly informed of the situation but we realized that our main concern was our customers. We needed to take care of them. The information coming from suppliers was required at the time of the crisis.

The situation was overwhelming for the organization. One supplier that was interviewed stated the following comment: 
We did not want to bother the organization. We wanted to know what was going on but felt we couldn't call them or ask questions. They were too busy dealing with customers and the media.

During the investigation, two slicing machines in the plant were found to be carrying listeria and the organization indicated these machines as the likely source. A conflict between the supplier and the focal organization became apparent which reflects a lack of interdependency (Pang, Cropp and Cameron 2006). However, the machine supplier was quick to react and stated that the slicing machines were safe:

We insisted that there has never been a serious food safety issue with our machines. There are nearly 300 of these slicing machines installed at processing plants around the world, and an estimated 2.3 billion kilograms of sliced meat have been produced over the last 13 years without any safety concerns. All instructions are clear and effective for the operation, maintenance and sanitation of these machines.

The organization did not seem to have a sound working relationship with that specific supplier before the crisis occurred. The dysfunctional relationship became evident during the crisis.

Based on this evidence, the organization seemed to have focused its efforts mostly on demand. The crisis readiness at the focal organization can therefore be considered as far-from-equilibrium.

\section{Discussion}

This case has been analyzed to examine why the crisis occurred. This case study suggests that a detailed crisis management plan does not guarantee crisis immunity for any organization. Reaching an equilibrium point between supply and demand may not prevent crises. Nonetheless, the evidence consulted in this paper suggests that supply or demand overdependence may influence how an organization manages a crisis. The incident is also evidence that an organization should set the rules of engagement between agents but not necessarily dictate their actions. Information should flow easily. In this case, the organization has shown demand overdependence (see Figure 1). It was not surprising that the focus was on markets and less so on supply. Markets are amoral and they allow organizations to act in accordance with their interests and impose some rules on how those interests are expressed. The organization's interests lie in demand-centric needs which have diminished its capacity to deal with a crisis.

In this case, there were serious breakdowns at the systemic level. The crisis confirms that focal organization has not effectively foreseen and confronted systemic risks that resulted in serious disruptions in food safety systems. Risk-management and oversight arguably focuses too much on the idiosyncratic risk that affects an individual firm and too little on the systemic issues that could affect the food industry as a whole. To put it somewhat differently, the conventional risk-management framework today focuses too much on the threat to a firm from its own mistakes and too little on the potential for mistakes to be correlated across firms. Effective food safety requires that firms think beyond the scope of their own operations. 
The public and the private sector should proceed to focus more on systemic issues in food safety architecture. There is no evidence that such a crisis will not happen again. Based on interviews conducted for this study, the organization's attitude during the crisis prevented any stakeholders to foresee opportunities to learn and change methods. In times of crisis, organizations create ways for all stakeholders to communicate amongst one another (Levick and Pudles, 2007). It is likely that non-linear connectedness and interdependence will continue to be deficient.

\section{Conclusion}

Although the findings of this study provide useful information regarding managing crisis in a multi-stakeholders environment, they should be viewed as exploratory. Additional adjustments to both the questions asked and the sample would provide broader generalizations. More analysis of the synthesis model in other sectors may prove beneficial in future research.

There are some possible limitations to our investigation. The case study was restricted to the input of only 5 respondents. Future studies may wish to investigate different perspectives to allow for more generalization. Another possible limitation is the use of the only one function within the supply chain. More research and case studies need to be carried out in crisis management in a multi-stakeholder context because very little academic research exists in this area despite numerous examples.

As evidenced by our findings, no single, one-size-fits-all crisis strategy plan can be adequate in a multi-stakeholder environment. In a crisis strategy plan, flexibility is a must because not every crisis is similar in scope or severity. That insight is most certainly pertinent to the food industry. In addition, an organization's approach with supply chain management can be critical in determining its effectiveness in dealing with a crisis. Again, while accepting that the point of equilibrium is impossible, it should remain the focal organization's ultimate goal. Finally, distribution forces will vary between functions of the supply chain which could alter the focal organization's strategy to attain the point of equilibrium.

\section{References}

Acquier, Aurelien and Sebastien Gand, Mathias Szpirglas (2008). From Stakeholder to Stakeholder Management in Crisis Episodes: A Case Study in a Public Transportation Company. Journal of Contingencies and Crisis Management, 16(2), 101-114.

Aldoory, Linda and Mark A Van Dyke (2006). The roles of perceived "shared” involvement and information overload in understanding how audiences make meaning of news about bioterrorism. Journalism and Mass Communication Quarterly, 83(2), 346-361.

Autry, Chad and Stanley E Griffis (2008). Supply chain capital: the impact of structural and relational linkages on firm execution and innovation. Journal of Business Logistics, 29(1), 157-IX. 


\section{Al Macrothink}

Research in Applied Economics

ISSN 1948-5433

2009, Vol. 1, No. 1: E4

Attaran, Amir and Noni MacDonald, Matthew B Stanbrook, Barbara Sibbald, Ken Flegel, Rajendra Kale, Paul C Hébert (2008). Listeriosis is the least of it. Canadian Medical Association. Journal, 179(8), 739-40, 743-4.

Bayley, Clare and Simon French. (2008). Designing a Participatory Process for Stakeholder Involvement in a Societal Decision. Group Decision and Negotiation, 17(3), 195-210.

Blattberg, R. C. \& S. A. Neslin (1990), Sales Promotion- Concepts. Methods, and Strategies. Englewood Cliffs, NJ: Prentice-Hall, Inc.

Bonnell, Gregory (26 August 2008). Canadians entitled to expect safe food, Harper says of listeria outbreak. The Canadian Press.

Charlebois, Sylvain (2008). The gateway to a Canadian market-driven agricultural economy :A framework for demand chain management in the food industry. British Food Journal, 110(9), 882-897.

Charlebois, Sylvain and Ronald D. Camp II. (2007). Environmental uncertainty and vertical integration in a small business network.The case of Natural Valley Farms Inc.. Journal of Enterprising Communities, 1(3), 252-267.

Charlebois, Sylvain and JoAnne Labrecque. (2007). Processual Learning, Environmental Pluralism, and Inherent Challenges of Managing a Socioeconomic Crisis: The Case of the Canadian Mad Cow Crisis. Journal of Macromarketing, 27(2), 115-125.

Cheah, Eng Tuck and Wen Li Chan, Corinne Lin Lin Chieng (2007). The Corporate Social Responsibility of Pharmaceutical Product Recalls: An Empirical Examination of U.S. and U.K. Markets. Journal of Business Ethics, 76(4), 427-449.

Creedle, Ed (2007). Bon Appetit: Food Recalls and Illness Reinforce a Need For Better Risk Management. Risk Management, 54(7), 40-44.

Curry, Laurie (2002). Food safety: An industry perspective. Canadian Journal of Dietetic Practice and Research, 63(1), Insert 3-4.

Desmarchelier, Patricia and Elizabeth A Szabo (2008). Innovation, food safety and regulation. Innovation : Management, Policy \& Practice, 10(1), 121-131.

Effective crisis communication; moving from crisis to opportunity. (2007, August). Reference and Research Book News, 22(3).

Emerson, R. M. (1962), Power-Dependence Relations, American Sociological Review, 27, 31-41.

Fischer, Arnout R. H. and Lynn J. Frewer, Maarten J. Nauta (2006). Toward Improving Food Safety in the Domestic Environment: A Multi-Item Rasch Scale for the Measurement of the Safety Efficacy of Domestic Food-Handling Practices. Risk Analysis, 26(5), 1323-1338. 


\section{Al Macrothink}

Research in Applied Economics

ISSN 1948-5433

2009, Vol. 1, No. 1: E4

Franck L. B. Meijboom Tatjana VisakFrans W. A. Brom (2006). From Trust to Trustworthiness: Why Information is not Enough in the Food Sector. Journal of Agricultural and Environmental Ethics, 19(5), 427-442.

González-Herrero Alfonso and Suzanne Smith (2008). Crisis Communications Management on the Web: How Internet-Based Technologies are Changing the Way Public Relations Professionals Handle Business Crises. Journal of Contingencies and Crisis Management, 16(3), 143-153.

Hudson, Chris and John Hudson (2008). Guaranteeing quality in the EU: who gains most?, Journal of Regulatory Economics, 33(3), 283-298.

Jacques, Tony (2008). A case study approach to issue and crisis management Schadenfreude or an opportunity to learn?. Journal of Communication Management, 12(3), 192-203.

Jamali, Dima (2008). A Stakeholder Approach to Corporate Social Responsibility: A Fresh Perspective into Theory and Practice. Journal of Business Ethics, 82(1), 213-231.

Kornelis, Marcel and Janneke de Jonge, Lynn Frewer, Hans Dagevos (2007). Consumer Selection of Food-Safety Information Sources. Risk Analysis, 27(2), 327-335.

Kennedy, Jean and Michelle Worosz, Ewen C Todd, Maria K Lapinski (2008). Segmentation of US consumers based on food safety attitudes. British Food Journal, 110(7), 691-705.

Kotler, P. (1994). Marketing Management (8e). Engelwood Cliffs: Prentice-Hall.

Lagadec, Patrick (2004). Understanding the French 2003 heat wave experience: beyond the heat, a multi-layered challenge, Journal of Contingencies and Crisis Management, Vol. 12 No. 4, pp. 160-9.

Levick, Richard and Gary A Pudles (2007). When Bad Things Happen to Good Companies. Risk Management, 54(2), 6.

Lindgreen, Adam (2003). Trust as a valuable strategic variable in the food industry: Different types of trust and their implementation. British Food Journal, 105(6/7), 310-327.

McCargar, L, Hanning, RM, Jessup, L, Lambraki, I, MacDonald, C, Minaker, L. (2003). A web-based approach to assessment of food intake and behaviour of school children and adolescents. Canadian Journal of Dietetic Practice and Research, 64(2), S110-S111.

Miller, Roxanne Greitz (2007). The pet food recall puzzle: Who, what, why, and how much?, Science Scope, 31(2), 10-12.

Murphy, Priscilla (1996). Chaos theory as a model for managing issues and crises. Public Relations Review, 22(2), 95.

Nabe, Jonathan (2003). Food safety in the biotech era. Reference \& User Services Quarterly, 43(1), 9-13. Retrieved October 27, 2008.

Norbert, Hirschauer and Stefan Zwoll (2008). Understanding and managing behavioural risks: the case of malpractice in poultry production. European Journal of Law and Economics, 
26(1),27-60.

Palazzo, Guido and Andreas Georg Scherer (2006). Corporate Legitimacy as Deliberation: A Communicative Framework. Journal of Business Ethics, 66(1), 71-88.

Pang, Augustine and Fritz Cropp, Glen T. Cameron (2006). Corporate crisis planning: tensions, issues, and contradictions. Journal of Communication Management,10(4), 371-389.

Paraskevas, Alexandros (2006). Crisis management or crisis response system A complexity science approach to organizational crises. Management Decision, 44(7), 892-907.

Pauchant, T.C., \& Mitroff, I.I. (1992). Crisis Management as an Ethical Activity: Myths and Methods, in T.C. Pauchant and I.I. Mitroff. Transforming the Crisis-Prone Organization: Preventing Individual, Organizational and Environmental Tragedies. San Francisco, CA: Jossey-Bass Publishers, p. 184-193.

Potts, Michelle and Roy Nelson (2008). Understanding the effect of stigmatization on food consumer knowledge, perception and behaviour in Northern Ireland. International Journal of Consumer Studies, 32(4), 366-373.

Reynolds, Scott J. and Frank C. Schultz, David R. Hekman (2006). Stakeholder Theory and Managerial Decision-Making: Constraints and Implications of Balancing Stakeholder Interests. Journal of Business Ethics, 64(3), 285-301.

Rhee, Yunna (2008). Risk communication management: a case study on Brookhaven National Laboratory. Journal of Communication Management, 12(3), 224-242.

Ritchie, Bob and Clare Brindley (2007). Supply chain risk management and performance A guiding framework for future development. International Journal of Operations \& Production Management, 27(3), 303-322.

Robert, B. and Lajtha, C. (2002), A new approach to crisis management, Journal of Contingencies and Crisis Management, Vol. 10 No. 4, pp. 181-91.

Roloff, Julia (2008). Learning from Multi-Stakeholder Networks: Issue-Focussed Stakeholder Management. Journal of Business Ethics, 82(1), 233-250.

Robson, C. (1993). Real world research: a resource for social scientists and practitioner-researchers, Blackwell, Orford.

Roth, Aleda V and Andy A Tsay, Madeleine E Pullman, John V Gray (2008). Unraveling the food supply chain: strategic insights from china and the 2007 recalls. Journal of Supply Chain Management, 44(1), 22-39.

Shang, Wenjing and Neal H Hooker (2005). Improving recall crisis management: should retailer information be disclosed? Journal of Public Affairs, 5(3/4), 329-341.

Surak, John G (2007). A Recipe for Safe Food: ISO 22000 and HACCP. Quality Progress, 40(10), 21-27. 


\section{Macrothink}

Research in Applied Economics

ISSN 1948-5433

2009, Vol. 1, No. 1: E4

Wei-Jiat Tan, Peter Enderwick. (2006). Managing threats in the global era: The impact and response to SARS. Thunderbird International Business Review, 48(4), 515.

Tew, Paula Johnson and Zhen Lu, George Tolomiczenko, Joanne Gellatly (2008). SARS: lessons in strategic planning for hoteliers and destination marketers. International Journal of Contemporary Hospitality Management, 20(3), 332-346.

Towner, Emil B (2008). Crisis management by apology. Review of medium_being_reviewed title_of_work_reviewed_in_italics. Business Communication Quarterly, 71(2), 261.

Walker, Vern (2008). Trade in Food: Regulatory and Judicial Approaches in the EC and the WTO. Review of medium_being_reviewed title_of_work_reviewed_in_italics. Common Market Law Review, 45(1), 274-277.

Wang, Jia (2008). Developing Organizational Learning Capacity in Crisis Management.

Advances in Developing Human Resources, 10(3), 425.

Yin, R. (1993). Applications of case study research, Sage publishing, Newbury Park, CA.

Yin, R. (1994). Case study research methods, $2^{\text {nd }}$ ed., Sage publication, Newbury Park, CA. 